\title{
Treating attention-deficit/hyperactivity disorder beyond symptom control alone in children and adolescents: a review of the potential benefits of long-acting stimulants
}

\author{
Jan Buitelaar • Rossella Medori
}

Received: 3 December 2008/ Accepted: 26 August 2009/Published online: 13 October 2009

(C) The Author(s) 2009. This article is published with open access at Springerlink.com

\begin{abstract}
Attention-deficit/hyperactivity disorder(ADHD), one of the most common neuropsychiatric conditions of childhood, often has a chronic course and persists into adulthood in many individuals. ADHD may have a clinically important impact on health-related quality of life in children, a significant impact on parents' emotional health and interfere with family activities/cohesion. To date, the main targets of ADHD treatment have focused on reducing the severity of symptoms during the school day and improving academic performance. However, the treatment of ADHD should reach beyond symptom control to address the issues of social competencies and improvement of health-related quality of life from the perspectives of individuals with ADHD and their families, to support them in reaching their full developmental potential. Methylphenidate (MPH) is recognised as the first-line choice of pharmacotherapy for ADHD in children and adolescents. This paper focuses on the importance and benefits to child development of ADHD symptom control beyond the school day only, i.e. extending into late afternoon and evening and uses the example of an extended-release MPH formulation $\left(\mathrm{OROS}^{\circledR} \mathrm{MPH}\right)$ to demonstrate the potential
\end{abstract}

J. Buitelaar $(\square)$

Department of Psychiatry, UMC St Radboud,

P.O. Box 9101, 6500 HB Nijmegen, The Netherlands

e-mail: j.buitelaar@psy.umcn.nl

J. Buitelaar

Karakter Child and Adolescent Psychiatry University Centre,

Nijmegen, The Netherlands

R. Medori

Laimer Str. 44, 80639 Munich, Germany

e-mail: RMedori@hotmail.com benefits of active full day coverage (12 h) with a single daily dose. Concerns of long-term stimulant treatment are also discussed.

Keywords ADHD - Children - Quality of life · Methylphenidate $\cdot$ OROS $^{\circledR}$ MPH

\section{Introduction}

Attention-deficit/hyperactivity disorder (ADHD) is one of the most common neuropsychiatric conditions of childhood, with prevalence generally estimated at $4-12 \%[8,13$, $28,58,81]$. ADHD is characterised by a chronic pattern of symptoms of inattention, impulsivity and hyperactivity, which are more present than absent in affected individuals [2]. The differentiation between ADHD and normal behaviour is based on the frequency of inappropriate behaviour, according to norms for age and IQ, and on the resulting impairment of functioning in different settings, for example, the child's behaviour and ability to accomplish tasks at home, at school, or in the community. Children with ADHD frequently have a number of co-existing disorders, such as conduct disorder, anxiety, depression, oppositional defiant disorder and obsessive disorder [12]. ADHD has also been associated with substance abuse and criminal behaviour [37, 59, 69]. Moreover, compared with non-affected children and adolescents, those with ADHD are at higher risk of sustaining accidental injuries, and requiring emergency department visits and hospitalisations $[20,41]$.

The effects of ADHD on a child's development may be far-reaching. While some effects are a direct consequence of the condition itself (e.g. poor classroom behaviour, impaired executive functioning and decreased classroom 
productivity), many relate to the resulting impairment of social interactions, academic achievement and emotional development [6]. Data suggest that children with ADHD are more likely to function poorly at home and at school, disrupt family and peers relationships, and suffer from low self-esteem [37, 45, 62]. Indeed, such findings were highlighted by the results of a recent pan-European survey, in which parents of children (8-18 years) with ADHD and without ADHD (normative population sample) completed an on-line questionnaire about the impact of their child's ADHD on everyday activities, general behaviour and family relationships [19]. Compared with the normative population sample, parents reported that ADHD children consistently displayed more demanding, noisy, disruptive, disorganised and impulsive behaviour. Likewise, a number of everyday activities (meal times, homework, playing alone, playing with other children, following family routines, individual leisure activities and group leisure activities) were also reported to be adversely affected by ADHD. Furthermore, parents reported that ADHD impacted negatively on all relationships, particularly those between the parent and child, child and their siblings and the child and other children [19].

From an early age, children with ADHD exhibit difficulties with attention and impulse control, and in modulating their behaviour as the situation demands. Evidence suggests that unless children achieve minimal social competence by around the age of 6-8 years, they have a high probability of being at risk of social difficulties throughout life [36]. While the child-parent relationship is important for personality development, peer relationships make a large contribution to social and cognitive development, being an integral part of good social competencies. Indeed, the single best childhood predictor of adult adaptation may not be IQ, academic success, or classroom behaviour, but the adequacy with which a child interacts with other children [36]. As such, children who are aggressive and disruptive, unable to sustain close relationships with other children and who cannot establish a place for themselves in peer culture are seriously 'at risk'.

This paper focuses on the importance and benefits to child development of managing ADHD symptoms beyond the school day only, i.e. extending into late afternoon and evening. Given the potential advantages of managing ADHD symptoms outside of the school environment, there has recently been great interest in the use of long-acting stimulant preparations. Indeed, current international guidelines for the management of ADHD recommend the use of long-acting formulations to reduce the need for in-school dosage and the likelihood of diversion [53, 70]. To date, a number of long-acting methylphenidate (MPH) formulations, with different pharmacological profiles, have been developed, including Equasym $\mathrm{XL}^{\circledR}$, Ritalin $\mathrm{LA}^{\circledR}$,
Metadate $\mathrm{CD}^{\circledR}$ and Concerta $\mathrm{XL}^{\circledR}$. This paper discusses the benefits of the use of long-acting MPH preparations, especially $\operatorname{OROS}^{\circledR} \mathrm{MPH}$, to exemplify the potential advantages of coverage over the active day for the child or adolescent with ADHD.

\section{Extending the period of symptom control}

The treatment of children with ADHD requires a comprehensive multimodal approach in which pharmacotherapy is an integral part of the treatment plan [70, 79, 104]. Current treatment guidelines suggest that children with ADHD benefit from medical therapy with MPH $[33,90]$. Atomoxetine, a non-stimulant norepinephrinespecific re-uptake inhibitor, is also approved for the treatment of ADHD in children aged $\geq 6$ years and adolescents [16].

Pharmacotherapy for attention-deficit/hyperactivity disorder

\section{Effects of atomoxetine and methylphenidate on attention-deficit/hyperactivity disorder}

Newcorn et al. [72] performed a large placebo-controlled, double-blind, cross-over study to compare the response rates of OROS MPH and atomoxetine, in patients with ADHD (aged 6-16 years). After 6 weeks of treatment, the proportion of patients responding to OROS MPH was significantly higher than the proportion of patients responding to atomoxetine (56 vs. $45 \%$ respectively; $P=0.02)$. For patients previously treated with a stimulant $(n=301)$, the response rate compared to placebo was significantly greater for OROS MPH (51 vs. 23\%, respectively; $P=0.002$ ) but not for atomoxetine (37 vs. $23 \%$, respectively; $P=0.09$ ). The response rate for OROS MPH was higher to that for atomoxetine $(P=0.03)$. In patients who were stimulant-naïve at study entry $(n=191)$, the response rates for both atomoxetine $(57 \% ; P=0.004)$ and OROS MPH (64\%; $P \leq 0.001)$ were superior to the rate for placebo $(25 \%)$. The response rates for OROS MPH and atomoxetine were not significantly different $(P=0.43)$. There were no significant group differences in completion rates (atomoxetine 84\%, OROS MPH 82\%, placebo $77 \% ; P=0.42)$. In addition, the rates of discontinuation due to adverse events were low and similar for all treatments (atomoxetine 2\%, OROS MPH 2\%, placebo $3 \%$; $P=1.00$ ). In the second phase of the study, patients who were initially randomized to OROS MPH and completed the 6-week study were switched to atomoxetine $(n=178)$. At the end of the second phase, $34 \%$ of the patients switched to atomoxetine responded to either atomoxetine or 
OROS MPH but not both, $44 \%$ responded to both treatments and $22 \%$ did not respond to either treatment. Of the 70 patients who did not respond to OROS MPH in the initial trial, $43 \%$ subsequently responded to atomoxetine. Likewise, 29 (42\%) of the 69 patients who did not respond to atomoxetine had previously responded to OROS MPH. Atomoxetine and OROS MPH both produced robust improvements in symptoms in patients with ADHD; however, there was a statistically significant difference in efficacy (response) favouring OROS MPH. Data from the second part of the study suggest that there is a differential response to the two treatments in approximately one-third of patients [72]. This finding is consistent with practice guidelines that recommend changing to a different class of medication if there is poor response to or tolerance of the first agent used.

Kemner et al. [48] performed a large, community-based, open-label study to evaluate treatment outcomes in children (aged 6-12 years) with ADHD, randomized to either once-daily OROS MPH $(n=850)$ or atomoxetine $(n=473)$ for 3 weeks. To simulate clinical practice, investigators were allowed to select starting doses on the basis of their clinical judgment within the approved dose ranges of each drug. Investigator-rated ADHD rating scale (ADHD-RS) assessments showed that, compared with baseline scores, both treatments produced statistically significant reductions in ADHD symptoms at each time point. However, the OROS MPH group resulted in significantly greater reductions from baseline in ADHD-RS scores throughout the course of the study compared to the atomoxetine group [48]. At the primary endpoint (week 3), mean changes from baseline in ADHD-RS scores were 20.24 points for OROS MPH and 16 points for atomoxetine $(P<0.001)$. Statistically significant differences between treatment groups were also observed at week 1 and 2 $(P<0.001)$, and a posthoc analysis indicated that betweentreatment differences increased over time $(2.77,3.44$ and 4.24 at weeks 1, 2 and 3, respectively; $P<0.001)$. Subgroup analyses, based on previous treatment for ADHD, demonstrated that, in subjects with a history of stimulant usage, reductions in ADHD-RS scores were significantly greater for OROS MPH versus atomoxetine at weeks 1, 2 and 3 , whereas in subjects who were previously treatmentnaïve reductions in ADHD-RS scores were significantly greater for OROS MPH versus atomoxetine at week 3 only. It should be pointed out that, as the authors themselves state, the duration of the study may not have been sufficient, and the 3-week timepoint may, therefore, not have been representative of the full action of atomoxetine. The incidence of treatment-related adverse events did not differ significantly between groups (OROS MPH 22.5\%; atomoxetine $25.6 \%$ ). Most adverse events were categorised as mild and not serious [48]. In line with the findings of Newcorn et al., these results suggest greater ADHD symptom improvement with OROS MPH than with atomoxetine.

Wang et al. [112] conducted a 10-month randomised, double-blind study in outpatients with ADHD (aged 6-16 years) in China, Korea and Mexico to (1) examine whether atomoxetine is non-inferior to $\mathrm{MPH}$ in treating symptoms of ADHD, and (2) determine the tolerability of the two drugs. Patients were randomly assigned to oncedaily atomoxetine $(0.8-1.8 \mathrm{mg} / \mathrm{kg}$ per day; $n=164)$ or twice-daily MPH (0.2-0.6 mg/kg per day; $n=166)$. Primary efficacy assessment was the comparison of response rates $(\geq 40 \%$ reduction from baseline to endpoint in total score) on the parent-rated ADHD-RS. Results demonstrated that atomoxetine was non-inferior to $\mathrm{MPH}$ in improving ADHD symptoms based on response rates (atomoxetine 77.4\%; MPH 81.5\%; $P=0.404$ ). Treatmentemergent adverse events experienced significantly more frequently in the atomoxetine group compared with the MPH group, included anorexia (37.2 vs. $25.3 \% ; P=$ 0.024 ), nausea (20.1 vs. $10.2 \% ; P=0.014)$, somnolence (26.2 vs. $3.6 \% ; P<0.001)$, dizziness (15.2 vs. $7.2 \%$; $P=0.024)$ and vomiting (11.6 vs. $3.6 \% ; P=0.007)$. Atomoxetine-treated patients also experienced a small but significantly greater mean weight loss from baseline to endpoint than MPH-treated patients $(-1.2$ vs. $-0.4 \mathrm{~kg}$; $P<0.001)$ [112].

Two further open-label studies have also examined the efficacy and safety of atomoxetine and MPH in children with ADHD [52, 93]. Results from the first study by Kratochivl et al., which was a 10 -week, prospective, randomised, open-label trial in 228 children with ADHD, reported that both atomoxetine $(n=184)$ and MPH $(n=44)$ were associated with marked improvement in inattentive and hyperactive-impulsive symptom clusters as assessed by parents and investigators. However, no statistically significant differences between treatment groups were observed on the primary outcome measure (investigator rated ADHD-IV rating scale total score). Safety and tolerability were also similar between the two agents [52]. The second study, a subgroup analysis of the Kemner [93] study, was a 3-week, multicentre, randomised, open-label study that assessed treatment outcomes with OROS MPH $(n=125)$ and atomoxetine $(n=58)$ in African-American children with ADHD. Both treatments were associated with significant improvements in ADHD symptoms from baseline. However, patients who received OROS MPH demonstrated significantly greater improvements in total ADHD symptoms, inattentiveness and global improvement. The incidence of adverse events was similar in both treatment groups [93]. 
Focus on methylphenidate for attention-deficit/ hyperactivity disorder

MPH is the most frequently prescribed psychostimulant, and there is a substantial evidence base for the efficacy of MPH over treatment periods of up to 1 year and at doses of up to $60 \mathrm{mg} /$ day [103]. Both short- and long-acting (LA)/ extended-release (ER) formulations are available. Behavioural improvements resulting from treatment with psychostimulants include sustained attention, impulse and emotional control, reduction of task-irrelevant activity, diminishment of noisy and disruptive behaviour, and diminishment of aggression [5, 74]. Other benefits include improvements in working memory, persistence of effort, academic productivity, accuracy and handwriting [5, 38]. As a result of stimulant treatment, children with ADHD may become more compliant with parental and teacher instructions, be better able to sustain such compliance, and often become more cooperative with others [5]. Furthermore, ADHD children themselves describe improvements in their self-esteem as a result of symptom control with stimulant medication [5]. Consequently, the quality of social interactions, such as peer relations, is improved [5, 103]. Common side effects of psychostimulants include appetite loss, stomach ache, insomnia and headache [5]. Rebound hyperactivity and irritability may also occur as the medication wears off, and pre-existing tic disorders can be exacerbated in certain children [119].

In the multimodal treatment study of children with ADHD (MTA) [104], community care group subjects, who were treated by their own providers, principally received treatment with immediate-release (IR) MPH, which was administered at an average of 2.3 doses per day (i.e. providing approximately 8 - $\mathrm{h}$ coverage). The medical management group received IR MPH three-times daily, which provides 10-12-h coverage. Since medical management fared substantially better than community care on most ADHD outcome measures at 14 months of treatment, it might be inferred that improved symptom control is provided by extended treatment coverage, although the study was not designed to test this hypothesis. In addition, it should be noted that a prospective follow-up study, which was undertaken to determine any long-term effects, 6 and 8 years after childhood enrolment, of the randomly assigned 14-month treatments in the MTA study demonstrated that the originally randomized treatment groups did not differ significantly on repeated measures or newly analysed variables such as school grades, arrests, psychiatric hospitalisations and other clinically relevant outcomes [64].

In general, the effects of MPH usually last only about $4 \mathrm{~h}$ with an IR formulation, although 12-h coverage may be provided with three-times daily dosing [120]. However, a two- or three-times daily dosing regimen results in peaks and troughs in plasma concentrations, which might lead to 'waxing and waning' of behavioural symptom improvement throughout the day and, potentially, to rebound [98]. Optimal IR dosing may, therefore, require taking the next dose before the previous dose begins to wear off. The development of LA/ER preparations has allowed continuous effective management of the symptoms of ADHD over a longer time period, although their duration of effect varies [4]. In general, Metadate CD (Equasym XL) and Ritalin LA provide 8-h coverage, although their effect can be extended by the addition of an IR dose. OROS MPH provides 12-h coverage with a single daily dose [120]. OROS MPH delivers MPH in a unique pattern of immediate-release (a small bolus) followed by extended-release (ascending delivery profile). Delivery of an ascending drug delivery profile has been claimed to provide optimal efficacy over $12 \mathrm{~h}$, for example, from early morning through the period of homework and after-school social activities [77, 97].

\section{Psychosocial treatments for ADHD}

Although stimulant medication is the cornerstone of treatment for ADHD, numerous nonpharmacological treatments can be employed in combination with medication to assist in the lifelong management of the disorder. Today, a large evidence base exists for behavioural interventions, including parent training in effective child behaviour management, family therapy in problem solving and communication skills and school interventions, such as classroom behaviour medication methods and academic interventions, which has resulted in their classification as 'empirically validated treatments' $[7,18,66]$. In addition, social skills training with generalisation components, intensive summer treatment programmes and educational interventions have also shown promise in the treatment of ADHD [18].

\section{Targets of therapy and the potential advantages of extending the period of symptom control}

\section{Social competence}

As children should achieve minimal social competence by the age of 6-8 years to avoid being 'at risk' of social difficulties throughout life [36], an important outcome of a comprehensive ADHD treatment programme is the allround personality development of affected children and adolescents. Social and family functioning should, therefore, be included alongside school performance as goals of ADHD treatment. The time after school, when life may be 
less structured, is just as important as school time for a child with ADHD, in terms of developing personal and social skills. Treatment that lasts the full day might enable patients to develop both academic and social skills, thereby improving both functioning in and out of school and childpeer and child-parent interactions. Indeed, sustained improvements (up to 12 months) in global assessment scale scores and peer interaction have been reported in children with ADHD receiving OROS MPH [115]. Such an ADHD treatment option has been shown to improve driving performance and reduce the risk of car accidents [20, 37, 59, 67, 71].

Although appropriate treatment would also be expected to minimise the potential risk for drug and alcohol abuse and criminality [10, 116], this was not found to be the case in a recent study that compared delinquent behaviour and early substance use between children in the MTA study ( $n=487$; total population, i.e. including those who received medication and/or behavioural treatment, or standard community care) and those in a local normative comparison group $(n=272)$. Relative to the local normative comparison group, children in the MTA study demonstrated significantly higher rates of delinquency (27.1 vs. $7.4 \%$ at 36 months; $P=0.000$ ) and substance abuse (17.4 vs. $7.8 \%$ at 26 months; $P=0.001)$, suggesting that the cause-and-effect relationships between treatment for ADHD and delinquency are unclear [63].

Reduction of specific behaviours and/or symptoms of attention-deficit/hyperactivity disorder throughout a 12-h day

Two laboratory school studies have demonstrated that attention and behaviour improved significantly and were sustained for $12 \mathrm{~h}$, covering the school day, homework and other after-school activities, when children took OROS MPH once daily compared to placebo [77, 97].

In addition, once-daily treatment with OROS MPH has been shown to be at least as effective as IR MPH given three-times a day in double-blind studies. Results from a double-blind, within-subject study of the efficacy and duration of action of IR MPH three times a day and oncedaily OROS MPH, compared with placebo, demonstrated that on virtually all measures in natural and structured (laboratory) settings, both drugs were significantly different from placebo, but not different from each other [77]. These results were confirmed in a 28-day, double-blind clinical trial in 282 children, randomised to placebo, IR MPH three times a day, or OROS MPH once daily [121]. More recently, a prospective cross-over study of 30 children also demonstrated that ER MPH formulations (Ritalin LA, OROS MPH) provided an improvement for patients, which is in keeping with Ritalin IR efficacy through once-daily administration [29]. However, a 1month switching study (from IR MPH to OROS MPH) indicated that, unlike IR MPH, OROS MPH improved symptom control in the after-school period [84]. However, it is important to note that this was an open-label, non-randomized, dose-adjustment study and the extent to which raters may have been biased by their knowledge of medication cannot be assessed [84]. Similarly, results from a prospective study demonstrated that OROS MPH was effective during the late afternoon and homework time, and consistent with parents' preference, was finally prescribed in over twice as many children as Ritalin LA [29]. This management strategy has been substantiated in a randomized, controlled effectiveness trial of OROS MPH compared to usual care with IR MPH in children with ADHD [94]. Overall, OROS MPH showed statistically significant superiority to IR MPH on multiple outcome measures, including remission rate. Recent evidence from a 28-day, open-label trial suggests that behavioural improvements observed when children with ADHD are switched from IR MPH to OROS MPH may also be accompanied by improvements in neurocognitive function, although these findings have yet to be replicated in large-scale, controlled trials [49].

Of note, an open-label study that evaluated the tolerability and effectiveness of once-daily OROS MPH in children with ADHD reported that effectiveness was maintained throughout 12 months, as demonstrated by stable inattention and overactivity with aggression scale (IOWA), Conners ratings and sustained improvements in peer interaction and global assessment scale scores [115]; analysis at 24 months also demonstrated effective symptom control [114]. A large, double-blind, placebo-controlled, multicentre trial also confirmed the efficacy and safety of OROS MPH in the treatment of adolescents with ADHD [118].

\section{Comorbid anxiety}

Attention-deficit/hyperactivity disorder is associated with a high risk of psychiatric comorbidity, which extends past childhood and adolescence into adulthood [9]. Reports of the impact of comorbid anxiety on MPH treatment of ADHD (and vice versa) have been variable. A randomized, double-blind, placebo-controlled, crossover study, conducted in 22 nonanxious and 18 anxious children with ADHD, found that comorbid anxiety was associated with a less robust response to MPH treatment, particularly in terms of improvement of working memory [102]. Similarly, a short-term, fixed-dose investigation, conducted in 43 children with ADHD, found that subjects with comorbid anxiety had a significantly poorer response to MPH than those without anxiety [80]. Furthermore, a study comparing 20 children with ongoing core symptoms of ADHD, who 
had received $\geq 6$ months of psychostimulant treatment, with 20 age- and IQ-matched medication-naïve controls found that anxiety was significantly increased in children with ADHD who were treated with psychostimulant medication in the intermediate to long term [109]. Other studies have found that response to MPH in children with ADHD is unaffected by the presence of comorbid anxiety. For example, the MTA study found that stimulant medication was equally effective in reducing ADHD symptoms in patients with and without comorbid anxiety [44, 104]. Similarly, a 4-month, randomized, placebo-controlled trial, conducted in 91 children with ADHD, 38 of whom had comorbid anxiety, found that, when MPH dose is titrated as in standard clinical practice, the presence of comorbid anxiety influenced neither the efficacy nor the associated side effects of MPH treatment [23]. Furthermore, a study investigating the efficacy of sequential pharmacotherapy in 42 children with ADHD and comorbid anxiety not only found that response to MPH treatment was comparable with that observed in children with general ADHD, but also that a small but significant minority of children exhibited a clinically meaningful reduction in anxiety following treatment with stimulant monotherapy [1]. Suggested reasons for these discrepancies include differences in study design (e.g. the MTA study included individualised titration, 14 months of treatment and a monthly management strategy), in contrast to the short-term, fixed-dose designs of earlier investigations [104] and the fact that children with ADHD and comorbid anxiety are likely to present with more physiological symptoms than those without comorbid anxiety, which may be overlooked at the time of treatment initiation and subsequently incorrectly attributed to the treatment itself [23]. Further investigations, particularly over the longer term, are required in order to further clarify the interaction between MPH treatment and comorbid anxiety.

Promotion of overall well-being, health and resilience of children and adolescents

The measurement of ADHD treatment response is often limited to measuring symptoms; therefore, because so much focus has been on symptom reduction, less is understood about health-related quality of life (HRQoL) and functioning. In a survey of 131 children with ADHD, $68.7 \%$ of whom had a comorbid psychiatric disorder, the parent version of the child health questionnaire was used to measure physical health, psychosocial health, limitations in family activities and family cohesion [50]. Compared with children without ADHD, children with ADHD had comparable physical health, but clinically important deficits in HRQoL in all psychosocial domains, including role/social limitations as a result of emotional behavioural problems (self-esteem, mental health and general behaviour). In addition, children with ADHD had a significant impact on parents' emotional health and time to meet their own needs, and interfered with family activities and cohesion. Of note, results from a recent meta-analysis, which was undertaken to determine the relationship between a reduction of ADHD symptoms (assessed by the ADHD rating scale-IV-parent version [ADHDRS-IV-Parent:Inv) and improvements in functioning [assessed by the life participation scale for ADHD (LPS)] reported that patients' symptomatic improvements were reflected in improvements in their social and behavioural function as measured by the LPS. Correlation analysis revealed a moderate-tostrong association between changes in the LPS total versus ADHDRS-IV-Parent:Inv total $(r=-6.8)$ [14]. For a clear improvement in functional outcomes to become apparent, a decrease in ADHDRSIV-Parent:Inv total of 16-18 points was necessary, corresponding to a symptomatic score reduction of approximately 40-45\% [14].

A treatment offering effective symptom control throughout a 12-h day has the potential to promote feelings of well-being, good health and resilience and improved functioning among individuals with ADHD, although this association will need to be investigated further in future clinical trials. In a population that is already vulnerable to low self-esteem and problematic peer relationships [37, 45, 62], children with ADHD are likely to feel embarrassed by having to present themselves to a member of school staff every lunch-time to receive their medication [87]. The social stigma of having a psychiatric disorder can be particularly problematic for children and adolescents when they are at school or college and can lead to teasing and bullying by peers [97]. Moreover, aggressive and disruptive individuals with ADHD may not be accepted by their peer groups at school/college and after school/college activities and are, therefore, less likely to form close relationships. Indeed, in a study of 111 children with ADHD and 100 adolescents without an ADHD history [3], parents of probands reported fewer close friendships and greater peer rejection compared with the non-ADHD group, while probands reported that their friends were less involved in conventional activities compared with the non-ADHD group.

Compared to age-matched individuals without ADHD, young drivers with ADHD are 2-4 times more likely to have experienced a motor vehicle accident, over threetimes more likely to have incurred associated injuries and four-times more likely to have been at fault for such accidents $[67,68]$. In a randomized, crossover, single-blind pilot study, six male adolescents treated with OROS MPH demonstrated significantly less variability in driving performance and performed significantly better throughout the day (e.g. steering, braking, speed and collisions) than 
patients treated with IR MPH three-times daily, particularly in the evenings (at 20:00 h) [22]. In another study, the effects of OROS MPH, stimulant mixed amphetamine salts extended release (MAS XR) or placebo on driving were compared in 35 adolescents with ADHD using a driving simulator at 17:00, 20:00 and 23:00 h. OROS MPH resulted in less time driving off the road, fewer instances of speeding, less erratic speed control and less inappropriate use of brakes when compared with placebo. In terms of overall driving performance, OROS MPH was significantly superior to placebo, whereas MAS XR was not associated with better driving than placebo [21]. These findings were considered to be due to the once-daily delivery of OROS $\mathrm{MPH}$, which was designed to provide $12 \mathrm{~h}$ of continuous symptom control. OROS ${ }^{\circledR}$ MPH has also been shown to significantly improve driving performance compared with placebo and MAS XR [21].

Whilst debilitating for the child, ADHD has also been shown to adversely impact on parents' quality of life, placing a substantial burden on the family as a whole. Compared to parents with children with no significant problem behaviours, parents with children with externalising behaviours (e.g. hyperactivity, aggression) reported a more negative impact on social life, more negative and less positive feelings about parenting and higher child-related stress [24]. Moreover, some parents of ADHD children have reported levels of stress as high as those reported by parents of children with autism [24].

Compounding these effects, the behaviour of parents and teachers towards children with ADHD is likely to be different from that with those without ADHD; such reactions may exacerbate the reduction in overall functioning and quality of life of those involved. In a study examining the behaviour of children with externalising disorders in interaction with their mothers, hyperactivity was enhanced by the interaction between the impulsive behaviour of the child and the aversive maternal response [106]. Mothers of children with ADHD were more restrictive and negative towards their children and showed less adequate control than did mothers of children without externalising disorders. ADHD children paid less attention, were less assertive and helpless and were more impulsive than controls. The importance of changes in parenting behaviour for families of children with ADHD has been highlighted during the MTA study which examined treatment outcomes for objectively measured parenting behaviour [113]. The combination of medication management and intensive behaviour therapy produced significantly greater improvements in constructive parenting than did either treatment alone.

Symptom management that extends beyond the school day will enable children and adolescents to focus on their homework and achieve better academic grades. Such improvements in performance may result in feelings of self-satisfaction and increase self-confidence. Moreover, social acceptance, good relationships with peers and with families, and academic achievements may further reduce anxieties linked to poor relationships and underperformance.

\section{Adherence}

The requirement for multiple daily dosing of MPH increases the likelihood of poor adherence, particularly in adolescents, and poor persistence with therapy has been shown to be associated with increased maternal psychological distress, indifferent parenting, maternal overprotection/control, poor family support, decreased interaction with parents and increased problems at home [32]. In order to improve compliance, once-daily administration of MPH is required [32]. Indeed, compliance has been shown to be significantly better for patients with ADHD receiving OROS MPH than IR MPH [54], and the switching of children with poor adherence to IR MPH to OROS MPH is associated with a significant improvement in behavioural symptoms and family/school measures [17]. In addition, initial treatment with an ER MPH has been associated with longer treatment periods, fewer switches in therapy, increased patient persistence with therapy and a lower usage rate of emergency room services compared with initial treatment with IR MPH [47].

\section{Patient preference}

Clearly, taking a medication once a day is more convenient for both the individual taking the medication and for those having to administer it [97]. For the school, the inconvenience and responsibility of storing and dispensing a controlled medication is removed [56]. Indeed, in a 9-month open-label study involving over 1,000 individuals treated with OROS MPH, more than $86 \%$ of parents at 3 months gave increased convenience as a major reason for their preference [97]. Another study $(n=1,082)$ demonstrated that $77 \%$ of parents preferred OROS MPH to previous treatments, with convenience $(86 \%)$, duration $(75 \%)$ and smoothness $(71 \%)$ of effect being the main reasons for their choice [85]. Furthermore, preference rates of parents (of 64 children) for OROS MPH over IR MPH taken threetimes daily have been shown to be significant in a doubleblind, cross-over study (54 vs. $26 \%$, respectively; $P<0.05)$.

Embarrassment and stigma

MPH formulations requiring two- or three-times daily administration schedules require individuals with ADHD to 
take their medication at school or college. However, children and adolescents may not want to take their medication because it makes them feel different from their peers. In addition, the stigma of being an outsider, or being different from their peers, increases non-adherence with medication. A survey of attitudes of children to taking stimulant medication revealed that the majority disliked taking medication; 59\% of parents believed that their child's self-esteem suffered, while $68 \%$ of parents felt that their child was embarrassed by taking their medication [87]. The 12-h coverage provided by OROS MPH should be enough to make additional doses at school or college unnecessary, enabling treatment to be taken in the privacy of the home environment. This avoids the embarrassment of having to take medication in public and the associated stigma attached to having a psychiatric condition requiring medication [97].

Development of social and personal skills

Importantly, a therapy for ADHD should provide symptom control over the active day extending into the late afternoon and evening, i.e. time after school, when life is less structured. Indeed, results from the pan-European survey reported that $35-40 \%$ of parents stated that their child's ADHD symptoms needed to be more effectively treated during the afternoon and evening [19].

Such time is just as important as school time for a child in terms of building social and personal skills, including relationships with peers and family [36]. It may also allow for continued academic achievement, as it is designed to enable the child to better focus during homework time.

Extended symptom control in children and adolescents were reported in a study that assessed the impact of switching from IR MPH (10-60 mg/day) to OROS MPH (18, 36 or $54 \mathrm{mg}$ once-daily) [84]. Decreases in the two subsets (inattention/overactivity and oppositional/defiance) of the parent/caregiver IOWA Conners ratings were reported, while IOWA Conners teacher ratings were maintained. Consistent with the 12-h duration of action [77, 97, 120], changes in the parent/ caregiver IOWA Conners ratings suggest that OROS MPH improves symptom control in the after-school period. This has also been demonstrated in a 3-week open-label study in which children and adolescents were switched from IR MPH to OROS MPH [39]. Switching medication resulted in a significant positive effect as evidenced by caregivers' ratings of core symptoms on the IOWA Conners inattention/overactivity subscale. Corresponding ratings by teachers revealed the efficacy of OROS MPH was comparable to that of IR MPH. Global efficacy was rated as good/excellent by teachers for $55 \%$ of the cases, by caregivers for $79 \%$ and by investigators for $77 \%$. Given that previously the efficacy of OROS MPH has been shown to be comparable to IR MPH dosed three-times daily in children [77, 97, 121], lower ratings by teachers than parents/caregivers might have reflected differences in children's behaviour in the different environments.

\section{Acute tolerance}

There is suggestion that acute tolerance to MPH can develop over the course of the day, and that the method of MPH delivery determines whether efficacy is maintained during the afternoon [98]. Increasing the concentration of MPH throughout the day is thought to overcome the development of acute tolerance [99]. This has been demonstrated with the OROS preparation of MPH, which provides an initial low-dose MPH bolus and an ascending MPH delivery profile across the day, and maintains full efficacy for $12 \mathrm{~h}$ with once-daily oral administration [99].

\section{Other considerations}

In the same way that measurement of response to treatment has focused on symptoms rather than overall HRQoL, emphasis has also been given to measuring academic improvement as opposed to psychosocial impairment. In parallel, once-daily ER MPH formulations, with an effective duration of action of about $8 \mathrm{~h}$, have been developed. Consequently, these formulations have been positioned mainly to improve school performance, an area of obvious concern in individuals with ADHD. As MPH is a stimulant and a controlled substance, with possible adverse consequences, such formulations also aim to provide low drug exposure, in line with potential concerns over the safety and long-term effects of treatment.

Developments, such as OROS MPH, enable clinicians to extend symptom control beyond the school day into the late afternoon and evening [77, 99]. This may result in additional beneficial effects on an individual's physical, emotional and social well-being later in the day (Table 1), an increasing area of interest that remains to be examined in future clinical trials.

Child health measures, such as the child health questionnaire [55] and the child health and illness profile [92], have been developed to evaluate HRQoL from childhood through adolescence. By assessing the individual's physical, emotional and social well-being from the perspective of a parent, or the child/adolescent directly, such questionnaires are helpful in evaluating treatment interventions. The current move towards their incorporation in to clinical trials has been long awaited. 
Table 1 Potential benefits of symptom control extending into the evening for children and adolescents with attention-deficit/hyperactivity disorder

- Improved health (e.g. fewer comorbidities)

- Improved physical well-being, enabling greater participation in sporting activities

- Greater ability to focus later in the day on learning activities (e.g. homework), skilled activities (e.g. driving) and domestic activities

- Improved self-esteem, which may promote the desire for greater social interaction

- Enhanced feelings of well-being and a positive state of mind, which might encourage social interaction and improve relationships

- Increased ability and desire to meet friends later in the day

- Reduction in the risk of antisocial behaviour and involvement with the police

- Greater inclusion in everyday interactions with family members, improving the cohesiveness of the family unit

\section{Concerns of long-term stimulant treatment}

Medical concerns of full-day coverage with methylphenidate

\section{Insomnia}

Sleep disturbances are frequently reported by children with ADHD [75], and include differences in sleep onset and sleep latency [108]. Sleeplessness is also a frequent presenting problem for children on stimulant medications $[95,96]$. It is, therefore, necessary to determine whether insomnia is a side effect of the drug, due to re-emergence of symptoms as the effects of the medication wear off, or unrelated to medication [56]. In the situation of medication wear-off, full-day cover may help to alleviate the problem.

Results from a number of studies have demonstrated that OROS MPH does not induce significant adverse effects regarding sleep [29, 100, 115, 121]. No significant differences in sleep quality were found during a 1-month study comparing OROS MPH, IR MPH and placebo [121]. Sleep quality was reported to be good or excellent for the majority of children in all three treatment groups. Sleep quality was also rated good/excellent for $71 \%$ (282/398) of children with ADHD after 1 month and 74\% (134/182) after 12 months of treatment with OROS MPH [115]. Similarly, a rating of good/excellent was received for ability to fall asleep (53 and $63 \%$ at months 1 and 12 , respectively). Likewise, 7 days treatment with once-daily OROS MPH and three-times daily IR MPH had similar effects on sleep quality in a double-blind, cross-over study of 64 children with ADHD. Average sleep latencies were 39, 33 and $7 \mathrm{~min}$, and average true sleep durations were 7.5, 7.6 and $8 \mathrm{~h}$, during administration of OROS MPH, IR MPH and placebo, respectively [100].

\section{Growth}

Growth may be impacted with stimulant therapy, and appetite reduction may be seen at the beginning of treatment [103]. Indeed, results from a retrospective review of growth data from files of all newly treated patients with ADHD in one paediatric practice, reported that during the first 6 months on stimulant medication, $86 \%$ of children had a height velocity below the age-corrected mean and there was weight loss in $76 \%$ of children [82]. Overall, the mean height deficit during the first 2 years of treatment was approximately $1 \mathrm{~cm} /$ year, although these effects were not cumulative and continuing [82].

A review from 2002 by Rapport et al. of quantifiable side effects associated with MPH therapy for children with ADHD has suggested that effects on height and weight are mostly transient, dose-dependent and easily rectifiable with dosage adjustments. Moreover, these side effects are considered minor from a clinical perspective considering the overall improvement in behaviour and cognitive functioning observed in most children [83]. Indeed, assessment of treatment effects with OROS MPH on growth in an openlabel study found that, in general, children with ADHD gained both height and weight over time [29, 115]. Mean absolute weight increased by $2.6 \mathrm{~kg}$ (from $34.2 \mathrm{~kg}$ ) during the first 12 months $(n=407)$, following a $0.1-\mathrm{kg}$ decrease during the first month of treatment; mean absolute height increased steadily by $5.2 \mathrm{~cm}$ (from $137.1 \mathrm{~cm}$ ) [115]. Over 21 months $(n=178)$, mean absolute weight increased by $6 \mathrm{~kg}$ (from $33.2 \mathrm{~kg}$ ) and mean absolute height increased by $10.2 \mathrm{~cm}$ (from $135.4 \mathrm{~cm}$ ) [29]. Clinically insignificant effects on height and weight $(0.23 \mathrm{~cm}$ and $1.23 \mathrm{~kg}$, respectively, in 21 months) have been reported in another trial, with no associated benefit from drug holidays [91]. However, the effect of stimulant therapy on growth remains a matter of some debate, particularly given the results of a recent analysis that evaluated effects of stimulant medication on growth rates in the follow-up phase of the MTA study [101]. In this analysis, the stimulant-naïve school-age children demonstrated stimulant-related decreases in growth after initiation of treatment, without evidence of growth rebound [101]. These findings are in contrast to those of a recent quantitative analysis of longitudinal studies concerning the effects of stimulant medication on the height and weight of children with ADHD, which found that, although treatment with stimulant medication leads to statistically significant delays in height and weight, it is also associated with a statistically significant attenuation of these deficits over time [27]. As with IR stimulants, the effects of long-acting stimulants on growth were found to be dose-related, and the attenuation of growth deficits was also evident for long-acting as well as IR stimulant formulations [27]. However, there is currently 
no evidence to suggest whether full-day coverage might have greater effects on growth than short-term treatment. The authors of the review conclude that despite the apparent attenuation of height and weight deficits over time, and some data suggesting that ultimate adult growth parameters are unaffected by stimulant treatment, further research is required to clarify the effects of continuous treatment from childhood to adulthood [27].

\section{Epilepsy}

Although MPH is believed to lower the seizure threshold [103], clinical experience suggests that doses appropriate to clinical management of ADHD in children and adolescents with co-existing epilepsy do not increase seizure frequency, at least in those with well-controlled epilepsy [40]. More recently, a number of studies have confirmed that MPH may be safely used in patients with epilepsy and ADHD, and that there are no adverse effects on seizure severity and frequency with its use [34, 65, 107]. However, low baseline seizure rates, small numbers of patients and short observation periods limit the power of these studies to detect increases in seizure risk and further longer-term, randomized controlled studies are required [105].

\section{Tic disorders}

In a 12-month open-label study of OROS MPH in which 48 of 407 children had a prior history of tics [115], three children experienced worsening of tics, 12 no change, 10 improvement and 20 reported no tics during the study. A total of 23 of the 359 subjects with no known history of tics before the study reported new onset of tics and seven $(1.7 \%)$ children discontinued treatment because of tics. The incidence of tics in children with ADHD has been calculated using five studies of OROS MPH lasting up to 2 years [76]. Data from three placebo-controlled studies reported that the incidence of tics was not significantly different between OROS MPH and placebo, while an analysis of tic episodes per patient found no correlation between OROS MPH dose and frequency of tic episodes. Although the risk of tic episodes was higher in patients with a history of tics than in those with no history of tics, data suggested that OROS MPH does not significantly induce or exacerbate tics in children with ADHD [76].

\section{Cardiovascular risk}

Sympathomimetic amines, including MPH, have the propensity to increase heart rate and blood pressure. In children, effects on heart rate and blood pressure have been shown to be mostly transient, dose-dependent and easily rectified with dosage adjustments, and are therefore, considered minor [83]. Stimulant and non-stimulant medications used in adults with ADHD have been associated with minor, but statistically significant, changes in heart rate and blood pressure, although such changes have frequently been observed in those receiving placebo [117]. Indeed, results from a 1-month randomized controlled trial reported no significant differences in vital signs between children receiving OROS MPH, IR MPH and placebo [121]. Similarly, additional studies have reported no clinically meaningful changes in blood pressure or pulse after 1 and 2 years of treatment with OROS MPH for ADHD children with prior exposure to medication [29, 115].

Recently, there has been much discussion about the cardiovascular risks of stimulant drugs used to treat ADHD. Using the Food and Drug Administration's (FDAs) Adverse Event Reporting System, drug-related adverse events reviewed by the Drug Safety and Risk management Advisory Committee of the FDA included 25 cases (eight on MPH) of sudden death, 19 (seven on MPH) of whom were $\leq 18$ years of age [73]. On autopsy, some cases had undiagnosed congenital heart disease, which renders patients vulnerable to the effects of sympathomimetic amines (such agents increase contractility and, in turn, blood pressure). After reviewing this information, the committee acknowledged the potential benefits of stimulants in the treatment of children with ADHD but emphasised "more selective and restricted use, while increasing awareness of potential hazards" [73]. However, both the Academy of Child and Adolescent Psychiatry and the American Academy of Pediatrics have concluded that sudden cardiac death in persons taking medications for ADHD is a very rare event, occurring at rates no higher than those in the general population of children and adolescents. In addition, both of these groups also noted the lack of any evidence that the routine use of ECG screening before beginning medication for ADHD treatment would prevent sudden death [78].

\section{Psychiatric adverse events}

Treatment with MPH at usual doses in children and adolescents may result in treatment-emergent psychotic or manic symptoms, such as hallucinations, delusional thinking or mania. Indeed, some psychiatric adverse events are mentioned in the labelling for various MPH products. In addition, administration of MPH may also exacerbate symptoms of behaviour disturbance and thought disorder in patients with a pre-existing psychotic disorder. This may be of particular concern given that individuals with ADHD have a high rate of comorbid psychiatric disorders, especially conduct disorder, oppositional defiant disorder, depression, anxiety, bipolar disorder, learning disabilities and other disorders, such as mental retardation, Tourette's 
syndrome and borderline personality disorder [12]. Overall, such comorbidity has been shown to be associated with a high degree of impairment and a poor long-term prognosis $[30,89]$.

\section{Abuse potential}

There is concern that the use of stimulant medications to treat ADHD may play a role in the development of drug addiction [111]. However, when taken in clinical doses and within a clinical context there appears to be very little abuse potential [51, 103]. Rates of MPH misuse, as in its diversion towards illicit use, also appear to be low. A systematic meta-analysis of six studies on the use of stimulants in children who were followed into adolescence and young adulthood demonstrated that early stimulant treatment resulted in a protective effect against later substance use disorders, such as drug and alcohol use (odds ratio 1.9) [116]. However, a recent prospective, follow-up study, in which 112 children with ADHD were examined at baseline and again after 10 years of follow up, did not replicate these findings, instead demonstrating that stimulant treatment during childhood and adolescence neither increased nor decreased the risk for subsequent substance use disorders in young adulthood [11]. Furthermore, a recent prospective longitudinal study in which 176 white male children, aged 6-12 years, with ADHD, but without conduct disorder, were followed up in late adolescence and compared against 178 comparison subjects found that the risk of developing substance use disorder was significantly associated with age at first MPH treatment: the later the first treatment, the greater the chances of developing substance use disorder [60]. This association appeared to be accounted for by the development of antisocial personality disorder, which was not the result of age-related differences in early conduct problems [60]. The authors conclude that initiation of MPH treatment at an early age does not increase the risk of later substance abuse and may, in fact, have beneficial long-term effects [60]. Effective reduction in ADHD symptoms, such as conduct disorder, and improved academic performance and peer and family relationships may have a protective effect against the risk of later substance abuse [103]. These somewhat conflicting findings highlight the need for a better understanding of the natural history of ADHD and possible reasons for the high comorbidity observed between ADHD and substance abuse [111]. Further investigations are also required in order to examine whether low self-esteem and insecurity amongst individuals with ADHD, which may develop due to failures at school and in personal relationships [103], might be prevented or ameliorated by early treatment with an extended period of symptom management over the day.

\section{Suicide}

Several studies have shown a possible association between ADHD and suicide [43, 46]. Indeed, results from a review of the literature from 1966 to 2003 reported that a diagnosis of ADHD is associated with an increased risk of suicide in young males by worsening comorbid conditions, particularly conduct disorder and depression [43]. However, to date, there is no known association between administration of MPH and the risk of suicide.

\section{Rebound effects}

One of the major challenges of MPH treatment is 'wearingoff' or rebound effects [31]. This phenomenon may be reduced by the unique pattern of MPH delivery by OROS MPH, which minimises the 'peaks and troughs' in plasma concentrations associated with more frequent dosing and provides 12-h coverage [99]. Indeed, this has been specifically reported in a 44-year-old female patient who experienced severe rebound phenomena with pronounced concentration disturbances, unrest and dysphoric mood when treated three-times daily IR MPH which stopped when she was switched to once-daily OROS MPH [88].

\section{General concerns of stimulant use}

Some of the potential risks associated with MPH treatment (e.g. growth effects) may incite legitimate emotional reactions in parents, and decisions about medication may, therefore, be made without a clear analysis of the associated benefit:risk ratio. Concerns over the long-term effects of treatment may be exacerbated by the fact that MPH and amphetamine are stimulants, which are controlled substances [99]. Thus, in the minds of some patients and parents, links are made between the medication and drug abuse with its associated problems and consequences. Such beliefs may encourage parents to supervise treatment, leading to older children and adolescents reacting against increased parental control. Moreover, parental scepticism about the value and appropriateness of stimulant therapy may affect the child's attitude and overall compliance. The public, therefore, needs to be reassured that the efficacy and tolerability of MPH is generally proven; LA preparations may help overcome some concerns, since such formulations can enable symptoms to be conveniently controlled over the full day using a single dose.

\section{Balancing the risk:benefit ratio}

While the importance of treating ADHD is established [25, $79,86,103]$ and stimulants are usually the first-line treatment [79], a number of factors need to be taken into 
consideration when selecting a treatment and formulation for an individual, including concordance, compliance and difficulties with multiple doses and the preference of patients and caretakers [25]. Studies on the OROS MPH preparation, for example, have demonstrated symptomatic remission, improvement in academic achievement, improved social skills and a reduction in parental stress [42, 77, 94, 99, 115].

Although the individuals with ADHD and their families are of primary concern, the benefits of treatment may also extend to the utilisation and cost of health care resources; in the US these are significantly greater for children and adolescents with ADHD than for people without ADHD, making treatment cost-effective relative to no drug treatment $[15,25,35,57,61]$. However, estimates are likely to under-estimate the true costs of caring for children with this condition because much ADHD-related care occurs within school and mental health settings. OROS MPH has been reported to be associated with an incremental costeffectiveness ratio (ICER) of 9200 GBP per quality adjusted life-year (QALYs) gained, i.e. more QALYs and a net cost saving, compared with IR MPH, Equasym XL, atomoxetine and behavioural therapy. A study conducted in The Netherlands regarding the cost-effectiveness of treatment with OROS MPH for youths with ADHD for whom treatment with IR MPH is suboptimal concluded that OROS MPH was a cost effective treatment; the 10-year total costs between treatments were comparable (OROS MPH, 16,015 €; IR MPH 15,739 €), and the ICER for OROS MPH was $2004 €$ per QALY [26]. Additionally, a cost consequence analysis of the management of ADHD in the UK revealed that starting ADHD treatment with behavioural therapy alone resulted in the highest annual cost $(3,453 €)$, while starting ADHD treatment with IR MPH alone $(2,138 €)$ and OROS MPH alone $(2,187 €)$ generated similar costs [110].

\section{Conclusions}

For children and adolescents with ADHD, there is a need for treatment approaches that take into account the 24-h impact of the disorder and include all-day coverage with effective medication. Time after school, when life may be less structured, is just as important as school time for a patient with ADHD in terms of developing social and interpersonal skills. A number of long-acting MPH formulations are currently available, which have been shown to provide symptom control throughout the active day. Moreover, such formulations avoid the embarrassment of having to take medication in public and the associated stigma attached to having a psychiatric condition requiring medication.
It is envisaged that treatments that provide effective symptom control will also have the potential to improve patients' social functioning and overall quality of life. However, whilst much current research in ADHD has focused on the objective management of symptoms, the effect of stimulant medication on the everyday functioning and well-being of children with ADHD (e.g. ability to undertake homework, participate in after-school activities, develop social and personal skills and engage with friends and family) remains relatively unexplored. As such, further research, especially long-term studies, are required to examine the impact of stimulant medications on these important outcomes measures.

Acknowledgments The authors would like to thank Frances Gambling, Medicus International, for her editorial assistance, and Barbara Schäuble and Joop Van Oene who reviewed the manuscript on behalf of Janssen-Cilag. Editorial assistance was funded by Janssen-Cilag EMEA, Beerse, Belgium.

Conflict of interest statement Professor Jan Buitelaar has been employed as a consultant and participated in advisory board meetings and speakers bureau for Eli Lilly, Janssen-Cilag, USB, Shire, Medice, Bristol-Myers Squibb and Pfizer. Professor Jan Buitelaar is the Editorin-Chief of European Child and Adolescent Psychiatry. Dr Rossella Medori was an employee of Janssen-Cilag Ltd, the manufacturer of OROS $^{\circledR}$ MPH (Concerta XL), at the time of article development.

Open Access This article is distributed under the terms of the Creative Commons Attribution Noncommercial License which permits any noncommercial use, distribution, and reproduction in any medium, provided the original author(s) and source are credited.

\section{References}

1. Abikoff H, McGough J, Vitiello B, McCracken J, Davies M, Walkup J, Riddle M, Oatis M, Greenhill L, Skrobala A, March J, Gammon P, Robinson J, Lazell R, McMahon DJ, Ritz L (2005) Sequential pharmacotherapy for children with comorbid attention-deficit/hyperactivity and anxiety disorders. J Am Acad Child Adolesc Psychiatry 44:418-427

2. American Psychiatric Association (1994) Diagnsotic and statistical manual for mental disorders: fourth edition (DSM-IV). American Psychiatric Association, Washington, DC

3. Bagwell CL, Molina BS, Pelham WE Jr, Hoza B (2001) Attention-deficit hyperactivity disorder and problems in peer relations: predictions from childhood to adolescence. J Am Acad Child Adolesc Psychiatry 40:1285-1292

4. Banaschewski T, Coghill D, Santosh P, Zuddas A, Asherson P, Buitelaar J, Danckaerts M, Dopfner M, Faraone SV, Rothenberger A, Sergeant J, Steinhausen HC, Sonuga-Barke EJ, Taylor E (2006) Long-acting medications for the hyperkinetic disorders. A systematic review and European treatment guideline. Eur Child Adolesc Psychiatry 15:476-495

5. Barkley RA (2004) Adolescents with attention-deficit/hyperactivity disorder: an overview of empirically based treatments. J Psychiatr Pract 10:39-56

6. Barkley RA (1998) Attention-deficit hyperactivity disorder. A handbook for diagnosis and treatment, 2nd edn. The Guildford Press, New York 
7. Barkley RA (2002) Psychosocial treatments for attention-deficit/ hyperactivity disorder in children. J Clin Psychiatry 63(Suppl 12):36-43

8. Bener A, Qahtani RA, Abdelaal I (2006) The prevalence of ADHD among primary school children in an Arabian society. J Atten Disord 10:77-82

9. Biederman J (1998) Attention-deficit/hyperactivity disorder: a life-span perspective. J Clin Psychiatry 59:4-16

10. Biederman J (2003) Pharmacotherapy for attention-deficit/ hyperactivity disorder (ADHD) decreases the risk for substance abuse: findings from a longitudinal follow-up of youths with and without ADHD. J Clin Psychiatry 64:3-8

11. Biederman J, Monuteaux MC, Spencer T, Wilens TE, Macpherson HA, Faraone SV (2008) Stimulant therapy and risk for subsequent substance use disorders in male adults with ADHD: a naturalistic controlled 10-year follow-up study. Am J Psychiatry 165:597-603

12. Biederman J, Newcorn J, Sprich S (1991) Comorbidity of attention deficit hyperactivity disorder with conduct, depressive, anxiety, and other disorders. Am J Psychiatry 148:564-577

13. Bloom B, Dey AN, Freeman G (2006) Summary health statistics for US children: national health interview survey, 2005. Vital Health Stat 231:1-84

14. Buitelaar JK, Wilens TE, Zhang S, Ning Y, Feldman PD (2009) Comparison of symptomatic versus functional changes in children and adolescents with ADHD during randomized, doubleblind treatment with psychostimulants, atomoxetine, or placebo. J Child Psychol Psychiatry 50:335-342

15. Chan E, Zhan C, Homer CJ (2002) Health care use and costs for children with attention-deficit/hyperactivity disorder: national estimates from the medical expenditure panel survey. Arch Pediatr Adolesc Med 156:504-511

16. Characteristics SSoP http://www.keele.ac.uk/schools/pharm/ MTRAC/ProductInfo/verdicts/A/ATOMOXETINE.PDF

17. Chou WJ, Chou MC, Tzang RF, Hsu YC, Gau SS, Chen SJ, Wu YY, Huang YF, Liang HY, Cheng H (2009) Better efficacy for the osmotic release oral system methylphenidate among poor adherents to immediate-release methylphenidate in the three ADHD subtypes. Psychiatry Clin Neurosci 63:167-175

18. Chronis AM, Jones HA, Raggi VL (2006) Evidence-based psychosocial treatments for children and adolescents with attention-deficit/hyperactivity disorder. Clin Psychol Rev 26: 486-502

19. Coghill D, Soutullo C, d'Aubuisson C, Preuss U, Lindback T, Silverberg M, Buitelaar J (2008) Impact of attention-deficit/ hyperactivity disorder on the patient and family: results from a European survey. Child Adolesc Psychiatry Ment Health $2: 31$

20. Cox DJ, Humphrey JW, Merkel RL, Penberthy JK, Kovatchev B (2004) Controlled-release methylphenidate improves attention during on-road driving by adolescents with attention-deficit/ hyperactivity disorder. J Am Board Fam Pract 17:235-239

21. Cox DJ, Merkel RL, Moore M, Thorndike F, Muller C, Kovatchev B (2006) Relative benefits of stimulant therapy with OROS methylphenidate versus mixed amphetamine salts extended release in improving the driving performance of adolescent drivers with attention-deficit/hyperactivity disorder. Pediatrics 118:e704-e710

22. Cox DJ, Merkel RL, Penberthy JK, Kovatchev B, Hankin CS (2004) Impact of methylphenidate delivery profiles on driving performance of adolescents with attention-deficit/hyperactivity disorder: a pilot study. J Am Acad Child Adolesc Psychiatry 43:269-275

23. Diamond IR, Tannock R, Schachar RJ (1999) Response to methylphenidate in children with ADHD and comorbid anxiety. J Am Acad Child Adolesc Psychiatry 38:402-409
24. Donenberg G, Baker BL (1993) The impact of young children with externalizing behaviors on their families. J Abnorm Child Psychol 21:179-198

25. Excellence NIfC (2006) Technology appraisal guidance No. 13. Guidance on the use of methyphenidate (Ritalin, Equasym) for attention-deficit/hyperactivity disorder (ADHD) in childhood. National Institute for Clinical Excellence, October 2003. http://www.nice.org.uk

26. Faber A, van Agthoven M, Kalverdijk L (2006) Cost effectiveness of long-acting methylphenidate OROS (Concerta XL) in ADHD youths with suboptimal symptom control of immediate-release methylphenidate in The Netherlands. Poster presented at ISPOR 9th annual European congress, Copenhagen, Denmark, 28-31 Oct 2006

27. Faraone SV, Biederman J, Morley CP, Spencer TJ (2008) Effect of stimulants on height and weight: a review of the literature. J Am Acad Child Adolesc Psychiatry 47:994-1009

28. Faraone SV, Sergeant J, Gillberg C, Biederman J (2003) The worldwide prevalence of ADHD: is it an American condition? World Psychiatry 2:104-113

29. Favreau A, Deseille-Turlotte G, Brault F, Giraudeau B, Krier C, Barthez MA, Castelnau P (2006) Benefit of the extended-release methylphenidate formulations: a comparative study in childhood. Arch Pediatr 13:442-448

30. Fischer AG, Bau CH, Grevet EH, Salgado CA, Victor MM, Kalil KL, Sousa NO, Garcia CR, Belmonte-de-Abreu P (2007) The role of comorbid major depressive disorder in the clinical presentation of adult ADHD. J Psychiatr Res 41(12):991-996

31. Garland EJ (1998) Pharmacotherapy of adolescent attention deficit hyperactivity disorder: challenges, choices and caveats. J Psychopharmacol 12:385-395

32. Gau SS, Shen HY, Chou MC, Tang CS, Chiu YN, Gau CS (2006) Determinants of adherence to methylphenidate and the impact of poor adherence on maternal and family measures. J Child Adolesc Psychopharmacol 16:286-297

33. Greenhill LL, Halperin JM, Abikoff H (1999) Stimulant medications. J Am Acad Child Adolesc Psychiatry 38:503-512

34. Gucuyener K, Erdemoglu AK, Senol S, Serdaroglu A, Soysal S, Kockar AI (2003) Use of methylphenidate for attention-deficit hyperactivity disorder in patients with epilepsy or electroencephalographic abnormalities. J Child Neurol 18:109-112

35. Guevara J, Lozano P, Wickizer T, Mell L, Gephart H (2001) Utilization and cost of health care services for children with attention-deficit/hyperactivity disorder. Pediatrics 108:71-78

36. Hartup WW (1992) Having friends, making friends and keeping friends: relationships as educational contexts. Urban, IL: ERIC Clearing house on elementary and early childhood education. Eric Digest 345854

37. Hechtman L (2000) Assessment and diagnosis of attentiondeficit/hyperactivity disorder. Child Adolesc Psychiatr Clin N Am 9:481-498

38. Hechtman L, Abikoff H, Klein RG, Weiss G, Respitz C, Kouri J, Blum C, Greenfield B, Etcovitch J, Fleiss K, Pollack S (2004) Academic achievement and emotional status of children with ADHD treated with long-term methylphenidate and multimodal psychosocial treatment. J Am Acad Child Adolesc Psychiatry 43:812-819

39. Heger S, Trott GE, Meusers M, Schulz E, Rothenberger A, Rettig K, Medori R, Schreiner A, Remschmidt H (2006) Switching from a short-acting to a long-acting methylphenidate preparation: a multicentre, open study in children with ADHD. Zeitschrift fur Kinder and Jugendpsychiatrie Psychotherapie 34:257-265

40. Hemmer SA, Pasternak JF, Zecker SG, Trommer BL (2001) Stimulant therapy and seizure risk in children with ADHD. Pediatr Neurol 24:99-102 
41. Hoare P, Beattie T (2003) Children with attention deficit hyperactivity disorder and attendance at hospital. Eur J Emerg Med 10:98-100

42. Hoare P, Remschmidt H, Medori R, Ettrich C, Rothenberger A, Santosh P, Schmit M, Spender Q, Tamhne R, Thompson M, Tinline C, Trott GE (2005) 12-month efficacy and safety of OROS MPH in children and adolescents with attention-deficit/ hyperactivity disorder switched from MPH. Eur Child Adolesc Psychiatry 14:305-309

43. James A, Lai FH, Dahl C (2004) Attention deficit hyperactivity disorder and suicide: a review of possible associations. Acta Psychiatr Scand 110:408-415

44. Jensen PS, Hinshaw SP, Kraemer HC, Lenora N, Newcorn JH, Abikoff HB, March JS, Arnold LE, Cantwell DP, Conners CK, Elliott GR, Greenhill LL, Hechtman L, Hoza B, Pelham WE, Severe JB, Swanson JM, Wells KC, Wigal T, Vitiello B (2001) ADHD comorbidity findings from the MTA study: comparing comorbid subgroups. J Am Acad Child Adolesc Psychiatry 40:147-158

45. Johnson C, Mash EJ (2001) Families with children with ADHD: review and recommendations for future research. Clin Child Fam Psychol Rev 3:183-207

46. Kelly TM, Cornelius JR, Clark DB (2004) Psychiatric disorders and attempted suicide among adolescents with substance use disorders. Drug Alcohol Depend 73:87-97

47. Kemner JE, Lage MJ (2006) Effect of methylphenidate formulation on treatment patterns and use of emergency room services. Am J Health Syst Pharm 63:317-322

48. Kemner JE, Starr HL, Ciccone PE, Hooper-Wood CG, Crockett RS (2005) Outcomes of OROS methylphenidate compared with atomoxetine in children with ADHD: a multicenter, randomized prospective study. Adv Ther 22:498-512

49. Kim Y, Shin MS, Kim JW, Yoo HJ, Cho SC, Kim BN (2009) Neurocognitive effects of switching from methylphenidate-IR to OROS-methylphenidate in children with ADHD. Hum Psychopharmacol 24:95-102

50. Klassen AF, Miller A, Fine S (2004) Health-related quality of life in children and adolescents who have a diagnosis of attention-deficit/hyperactivity disorder. Pediatrics 114:e541-e547

51. Kollins SH (2003) Comparing the abuse potential of methylphenidate versus other stimulants: a review of available evidence and relevance to the ADHD patient. J Clin Psychiatry 64:14-18

52. Kratochvil CJ, Heiligenstein JH, Dittmann R, Spencer TJ, Biederman J, Wernicke J, Newcorn JH, Casat C, Milton D, Michelson D (2002) Atomoxetine and methylphenidate treatment in children with ADHD: a prospective, randomized, openlabel trial. J Am Acad Child Adolesc Psychiatry 41:776-784

53. Kutcher S, Aman M, Brooks SJ, Buitelaar J, van Daalen E, Fegert J, Findling RL, Fisman S, Greenhill LL, Huss M, Kusumakar V, Pine D, Taylor E, Tyano S (2004) International consensus statement on attention-deficit/hyperactivity disorder (ADHD) and disruptive behaviour disorders (DBDs): clinical implications and treatment practice suggestions. Eur Neuropsychopharmacol 14:11-28

54. Lage M, Hwang P (2004) Effect of methylphenidate formulation for attention deficit hyperactivity disorder on patterns and outcomes of treatment. J Child Adolesc Psychopharmacol $14: 575-581$

55. Landgraft JL, Abetz K, Ware JE (1996) The CHQ user's manual. The Health Institute, New England Medical Center, Boston

56. LeFever GB, Dawson KV, Morrow AL (1999) The extent of drug therapy for attention deficit-hyperactivity disorder among children in public schools. Am J Public Health 89:1359-1364

57. Leibson CL, Katusic SK, Barbaresi WJ, Ransom J, O'Brien PC (2001) Use and costs of medical care for children and adolescents with and without attention-deficit/hyperactivity disorder. JAMA 285:60-66

58. Lynch F, Mills C, Daly I, Fitzpatrick C (2006) Challenging times: prevalence of psychiatric disorders and suicidal behaviours in Irish adolescents. J Adolesc 29:555-573

59. Mannuzza S, Klein RG, Bessler A, Malloy P, LaPadula M (1993) Adult outcome of hyperactive boys. Educational achievement, occupational rank, and psychiatric status. Arch Gen Psychiatry 50:565-576

60. Mannuzza S, Klein RG, Truong NL, Moulton JL 3rd, Roizen ER, Howell KH, Castellanos FX (2008) Age of methylphenidate treatment initiation in children with ADHD and later substance abuse: prospective follow-up into adulthood. Am J Psychiatry 165:604-609

61. Marchetti A, Magar R, Lau H, Murphy EL, Jensen PS, Conners CK, Findling R, Wineburg E, Carotenuto I, Einarson TR, Iskedjian M (2001) Pharmacotherapies for attention-deficit/ hyperactivity disorder: expected-cost analysis. Clin Ther 23:1904-1921

62. McClure A, Prasad S, Poole L (2005) Functional outcomes of children with attention deficit hyperactivity disorder in the UK. Arch Dis Childhood 90:A48-A50

63. Molina BS, Flory K, Hinshaw SP, Greiner AR, Arnold LE, Swanson JM, Hechtman L, Jensen PS, Vitiello B, Hoza B, Pelham WE, Elliott GR, Wells KC, Abikoff HB, Gibbons RD, Marcus S, Conners CK, Epstein JN, Greenhill LL, March JS, Newcorn JH, Severe JB, Wigal T (2007) Delinquent behavior and emerging substance use in the MTA at 36 months: prevalence, course, and treatment effects. J Am Acad Child Adolesc Psychiatry 46:1028-1040

64. Molina BS, Hinshaw SP, Swanson JM, Arnold LE, Vitiello B, Jensen PS, Epstein JN, Hoza B, Hechtman L, Abikoff HB, Elliott GR, Greenhill LL, Newcorn JH, Wells KC, Wigal T, Gibbons RD, Hur K, Houck PR (2009) The MTA at 8 years: prospective follow-up of children treated for combined-type ADHD in a multisite study. J Am Acad Child Adolesc Psychiatry 48:484-500

65. Moore JL, McAuley JW, Long L, Bornstein R (2002) An evaluation of the effects of methylphenidate on outcomes in adult epilepsy patients. Epilepsy Behav 3:92-95

66. Murphy K (2005) Psychosocial treatments for ADHD in teens and adults: a practice-friendly review. J Clin Psychol 61:607-619

67. Murphy K, Barkley RA (1996) Attention deficit hyperactivity disorder adults: comorbidities and adaptive impairments. Compr Psychiatry 37:393-401

68. Nada-Raja S, Langley JD, McGee R, Williams SM, Begg DJ, Reeder AI (1997) Inattentive and hyperactive behaviors and driving offenses in adolescence. J Am Acad Child Adolesc Psychiatry 36:515-522

69. National Institute for Clinical Excellence (2000) Technology appraisal guidance No. 13. Guidance on the use of methyphenidate (Ritalin, Equasym) for attention-deficit/hyperactivity disorder (ADHD) in childhood. October

70. National Institute for Clinical Excellence (2006) Attention deficit hyperactivity disorder: diagnosis and management of ADHD in children, young people and adults 2006. http://www. nice.org.uk/guidance/index.jsp?action $=$ download\&o $=34227$

71. National Institute for Clinical Excellence (2003) Technology appraisal guidance No. 13. Guidance on the use of methyphenidate (Ritalin, Equasym) for attention-deficit/hyperactivity disorder (ADHD) in childhood

72. Newcorn JH, Kratochvil CJ, Allen AJ, Casat CD, Ruff DD, Moore RJ, Michelson D (2008) Atomoxetine and osmotically released methylphenidate for the treatment of attention deficit hyperactivity disorder: acute comparison and differential response. Am J Psychiatry 165:721-730 
73. Nissen SE (2006) ADHD drugs and cardiovascular risk. N Engl J Med 354:1445-1448

74. O'Driscoll GA, Depatie L, Holahan AL, Savion-Lemieux T, Barr RG, Jolicoeur C, Douglas VI (2005) Executive functions and methylphenidate response in subtypes of attention-deficit/ hyperactivity disorder. Biol Psychiatry 57:1452-1460

75. Owens JA, Maxim R, Nobile C, McGuinn M, Msall M (2000) Parental and self-report of sleep in children with attention-deficit/hyperactivity disorder. Arch Pediatr Adolesc Med 154:549555

76. Palumbo D, Spencer T, Lynch J, Co-Chien H, Faraone SV (2004) Emergence of tics in children with ADHD: impact of once-daily OROS methylphenidate therapy. J Child Adolesc Psychopharmacol 14:185-194

77. Pelham WE, Gnagy EM, Burrows-Maclean L, Williams A, Fabiano GA, Morrisey SM, Chronis AM, Forehand GL, Nguyen CA, Hoffman MT, Lock TM, Fielbelkorn K, Coles EK, Panahon CJ, Steiner RL, Meichenbaum DL, Onyango AN, Morse GD (2001) Once-a-day Concerta methylphenidate versus threetimes-daily methylphenidate in laboratory and natural settings. Pediatrics 107:E105

78. Perrin JM, Friedman RA, Knilans TK (2008) Cardiovascular monitoring and stimulant drugs for attention-deficit/hyperactivity disorder. Pediatrics 122:451-453

79. Pliszka S, American Academy of Child and Adolescent Psychiatry (2007) Practice parameter for the assessment and treatment of children and adolescents with attention-deficit/ hyperactivity disorder. J Am Acad Child Adolesc Psychiatry 46:894-921

80. Pliszka SR (1989) Effect of anxiety on cognition, behavior, and stimulant response in ADHD. J Am Acad Child Adolesc Psychiatry 28:882-887

81. Polanczyk G, de Lima MS, Horta BL, Biederman J, Rohde LA (2007) The worldwide prevalence of ADHD: a systematic review and metaregression analysis. Am J Psychiatry 164:942-948

82. Poulton A, Cowell CT (2003) Slowing of growth in height and weight on stimulants: a characteristic pattern. J Paediatr Child Health 39:180-185

83. Rapport MD, Moffitt C (2002) Attention deficit/hyperactivity disorder and methylphenidate. A review of height/weight, cardiovascular, and somatic complaint side effects. Clin Psychol Rev 22:1107-1131

84. Remschmidt H, Hoare P, Ettrich C, Rothenberger A, Santosh P, Schmidt M, Spender Q, Tamhne R, Thompson M, Tinline C, Trott GE, Medori R (2005) Symptom control in children and adolescents with attention-deficit/hyperactivity disorder on switching from immediate-release MPH to OROS MPH Results of a 3-week open-label study. Eur Child Adolesc Psychiatry 14:297-304

85. Robb A, Stein M (2002) Parent preference for OROS methylphenidate over methylphenidate tid. Poster presented at 155th annual meeting of the American Psychiatry Association, Philadelphia, 18-23 May 2002

86. Scottish Intercollegiate Guidelines Network (2001) Attention deficit and hyperkinetic disorders in children and young people. A national clinical guidelines No. 52. SIGN, Edinburgh

87. Sleator EK, Ulmann RK, von Neumann A (1982) How to hyperactive children feel about taking stimulatnts and will they tell their doctor? Clin Pediatr 21:474-479

88. Sobanski E, Alm B (2005) Long-acting methylphenidate. An alternative medical therapy for adult patients with attention deficit hyperactivity disorder. Nervenarzt 76:1412-1417

89. Sobanski E, Alm B, Krumm B (2007) Effect of subtype and psychiatric comorbidities on methylphenidate treatment in adults with attention-deficit hyperactivity disorder. Nervenarzt 78:328-337
90. Spencer T, Biederman J, Wilens T, Harding M, O’Donnell D, Griffin S (1996) Pharmacotherapy of attention-deficit hyperactivity disorder across the life cycle. J Am Acad Child Adolesc Psychiatry 35:409-432

91. Spencer TJ, Faraone SV, Biederman J, Lerner M, Cooper KM, Zimmerman B (2006) Does prolonged therapy with a longacting stimulant suppress growth in children with ADHD? J Am Acad Child Adolesc Psychiatry 45:527-537

92. Starfield B, Riley A, Ensminger M (2000) Manual for the child health and illness profile-child edition (CHIP-CE). The John Hopkins University, Baltimore, MD

93. Starr HL, Kemner J (2005) Multicenter, randomized, open-label study of OROS methylphenidate versus atomoxetine: treatment outcomes in African-American children with ADHD. J Natl Med Assoc 97:11S-16S

94. Steele M, Weiss M, Swanson J, Wang J, Prinzo RS, Binder CE (2006) A randomized, controlled effectiveness trial of OROSmethylphenidate compared to usual care with immediate-release methylphenidate in attention deficit-hyperactivity disorder. Can J Clin Pharmacol 13:e50-e62

95. Stein MA (1999) Unravelling sleep problems in treated and untreated children with ADHD. J Child Adolesc Psychopharmacol 9:157-168

96. Stein MA, Sarampote CS, Waldman ID, Robb AS, Conlon C, Pearl PL, Black DO, Seymour KE, Newcorn JH (2003) A doseresponse study of OROS methylphenidate in children with attention-deficit/hyperactivity disorder. Pediatrics 112:e404

97. Swanson J (2003) Compliance with stimulants for attention-deficit/ hyperactivity disorder: issues and approaches for improvement. CNS Drugs 17:117-131

98. Swanson J, Gupta S, Guinta D, Flynn D, Agler D, Lerner M, Williams L, Shoulson I, Wigal S (1999) Acute tolerance to methylphenidate in the treatment of attention deficit hyperactivity disorder in children. Clin Pharmacol Ther 66:295-305

99. Swanson J, Gupta S, Lam A, Shoulson I, Lerner M, Modi N, Lindemulder E, Wigal S (2003) Development of a new once-aday formulation of methylphenidate for the treatment of attention-deficit/hyperactivity disorder: proof-of-concept and proof-of-product studies. Arch Gen Psychiatry 60:204-211

100. Swanson J, Sadeh A, Lerner M (2001) Comparison of the impact of OROS methylphenidate HCL with methylphenidate tid and placebo on the sleep of children with ADHD. Reported in: Keating GM, McClellan K, Jarvis B. Methylphendiate (OROS formulation). CNS Drugs 15:495-503

101. Swanson JM, Elliott GR, Greenhill LL, Wigal T, Arnold LE, Vitiello B, Hechtman L, Epstein JN, Pelham WE, Abikoff HB, Newcorn JH, Molina BS, Hinshaw SP, Wells KC, Hoza B, Jensen PS, Gibbons RD, Hur K, Stehli A, Davies M, March JS, Conners CK, Caron M, Volkow ND (2007) Effects of stimulant medication on growth rates across 3 years in the MTA follow-up. J Am Acad Child Adolesc Psychiatry 46:10151027

102. Tannock R, Ickowicz A, Schachar R (1995) Differential effects of methylphenidate on working memory in ADHD children with and without comorbid anxiety. J Am Acad Child Adolesc Psychiatry 34:886-896

103. Taylor E, Dopfner M, Sergeant J, Asherson P, Banaschewski T, Buitelaar J, Coghill D, Danckaerts M, Rothenberger A, SonugaBarke E, Steinhausen HC, Zuddas A (2004) European clinical guidelines for hyperkinetic disorder-first upgrade. Eur Child Adolesc Psychiatry 13(Suppl 1):17-30

104. The MTA Cooperative Group (1999) A 14-month randomised clinical trial of treatment of strategies for attention deficit hyperactivity disorder. Arch Gen Psychiatry 56:1073-1086

105. Torres AR, Whitney J, Gonzalez-Heydrich J (2008) Attentiondeficit/hyperactivity disorder in pediatric patients with epilepsy: 
review of pharmacological treatment. Epilepsy Behav 12:217233

106. Trautmann-Villalba P, Gerhold M, Polowczyk M, Dinter-Jorg M, Laucht M, Esser G, Schmidt MH (2001) Mother-child interaction and externalizing disorders in elementary schoolchildren. Zeitschrift fur Kinder und Jugendpsychiatri Psychotherapie 29(4):263-273

107. van der Feltz-Cornelis CM, Aldenkamp AP (2006) Effectiveness and safety of methylphenidate in adult attention deficit hyperactivity disorder in patients with epilepsy: an open treatment trial. Epilepsy Behav 8:659-662

108. van der Heijden KB, Smits MG, Gunning WB (2006) Sleep hygiene and actigraphically evaluated sleep characteristics in children with ADHD and chronic sleep onset insomnia. J Sleep Res 15:55-62

109. Vance AL, Luk ES, Costin J, Tonge BJ, Pantelis C (1999) Attention deficit hyperactivity disorder: anxiety phenomena in children treated with psychostimulant medication for 6 months or more. Aust N Z J Psychiatry 33:399-406

110. Vanoverbeke N, Annemans L, Ingham M, Price M, Adriaenssen I (2003) A cost-consequence analysis of the management of attention deficit hyperactivity disorder (ADHD) in the UK. Poster presented at ISPOR 8th annual meeting, Arlington, VA, 18-21 May 2003

111. Volkow ND, Swanson JM (2008) Does childhood treatment of ADHD with stimulant medication affect substance abuse in adulthood? Am J Psychiatry 165:553-555

112. Wang Y, Zheng Y, Du Y, Song DH, Shin YJ, Cho SC, Kim BN, Ahn DH, Marquez-Caraveo ME, Gao H, Williams DW, Levine LR (2007) Atomoxetine versus methylphenidate in paediatric outpatients with attention deficit hyperactivity disorder: a randomized, double-blind comparison trial. Aust N Z J Psychiatry 41:222-230

113. Wells KC, Chi TC, Hinshaw SP, Epstein JN, Pfiffner L, NebelSchwalm M, Owens EB, Arnold LE, Abikoff HB, Conners CK, Elliot GR, Greenhill LL, Hechtman L, Hoza B, Jensen PS, March J, Newcorn JH, Pelham WE, Severe JB, Swanson J, Vitiello B, Wigal $\mathrm{T}$ (2006) Treatment-related changes in objectively measured parenting behaviours in the multimodal treatment study of children with attention-deficit/hyperactivity disorder. J Consult Clin Psychol 74:649-657

114. Wilens T, McBurnett K, Stein M, Lerner M, Spencer T, Wolraich M (2005) ADHD treatment with once-daily OROS methylphenidate: final results from a long-term open-label study. J Am Acad Child Adolesc Psychiatry 44:1015-1023

115. Wilens T, Pelham W, Stein M, Conners CK, Abikoff H, Atkins M, August G, Greenhill L, McBurnett K, Palumbo D, Swanson J, Wolraich M (2003) ADHD treatment with once-daily OROS methylphenidate: interim 12-month results from a long-term open-label study. J Am Acad Child Adolesc Psychiatry 42:424433

116. Wilens TE, Faraone SV, Biederman J, Gunawardene S (2003) Does stimulant therapy of attention-deficit/hyperactivity disorder beget later substance abuse? A meta-analytic review of the literature. Pediatrics 111:179-185

117. Wilens TE, Hammerness PG, Biederman J, Kwon A, Spencer TJ, Clark S, Scott M, Podolski A, Ditterline JW, Morris MC, Moore H (2005) Blood pressure changes associated with medication treatment of adults with attention-deficit/hyperactivity disorder. J Clin Psychiatry 66:253-259

118. Wilens TE, McBurnett K, Bukstein O, McGough J, Greenhill L, Lerner M, Stein MA, Conners CK, Duby J, Newcorn J, Bailey CE, Kratochvil CJ, Coury D, Casat C, Denisco MJ, Halstead P, Bloom L, Zimmerman BA, Gu J, Cooper KM, Lynch JM (2006) Multisite controlled study of OROS methylphenidate in the treatment of adolescents with attention-deficit/hyperactivity disorder. Arch Pediatr Adolesc Med 160:82-90

119. Wilens TE, Spencer TJ (2000) The stimulants revisited. Child Adolesc Psychiatr Clin N Am 9:573-603

120. Wolraich ML, Doffing MA (2004) Pharmacokinetic considerations in the treatment of attention-deficit hyperactivity disorder with methylphenidate. CNS Drugs 18:243-250

121. Wolraich ML, Greenhill LL, Pelham W, Swanson J, Wilens T, Palumbo D, Atkins M, McBurnett K, Bukstein O, August G (2001) Randomized, controlled trial of oros methylphenidate once a day in children with attention-deficit/hyperactivity disorder. Pediatrics 108:883-892 